Proc. Indian Acad. Sci. (Earth Planet. Sci.), Vol. 90, No. 3, Novenaber 1981, pp. 281.290

(c) Printed in India.

\title{
Water vapour content over two Indian sites tested for a millimeter-wave radio observatory
}

\author{
U N MAIYA*† and PATRICK DIERICH** \\ *Raman Research Institute, Bangalore 560 080, India \\ fPreseni ađdress : Vijaya College, Mulki 574 154, Karnataka State, India \\ **Observatory of Paris, 92190 Meudon, France
}

MS received 28 January 1981; reviscd 1 August 1981

\begin{abstract}
Measurements of the water vapour content over two possible sites for a millimeter-wave radio-observatory in South India are described. The results of the survey, made with an infrared spectral hygrometer built at the Meudon Observatory, France arc compared with those of similar surveys made at some other sites in Europe and America.
\end{abstract}

Keywords. Precipitable water vapour; millimeter-wave observatory; infrared spectral hygrometer.

\section{Introduction}

Microwave radiation coming from extra-terrestrial sources gets modified as it passes through the atmosphere and renches the earth's surface. Therefore, consideration of the atmospheric transparency forms an important aspect in evaluating the suitability of any site for a millimeter-wave telescope. In the spectral range of interest for such an observatory, the transparency is determined largely by the presence of water vapour, $\mathrm{O}_{2}$, clouds, aerosol and dust, turbulence and convection, because of the associated absorption, emission, scattering and refraction. Radio signals propagating through the atmosphere not only suffer attenuation and refraction but also are degraded by the noise due to emission and fluctuations there. Water vapour and $\mathrm{O}_{2}$ are the main molecular constituents which bring about these undesirable effects,(figure 1). The water vapour content varies over a wide range both with time and location whereas other dry components remain more or less constant. Therefore, the measurement of the amount of water vapour is important to determine to a first approximation the characteristics of radio propagation through the atmosphere (Gibbins et al 1975; Webster 1975; Greve 1978).

The present study was carried out to explore the merits of two sites for the location of a millimeter-wave telescope - Bangalore (elevation $950 \mathrm{~m}$, 


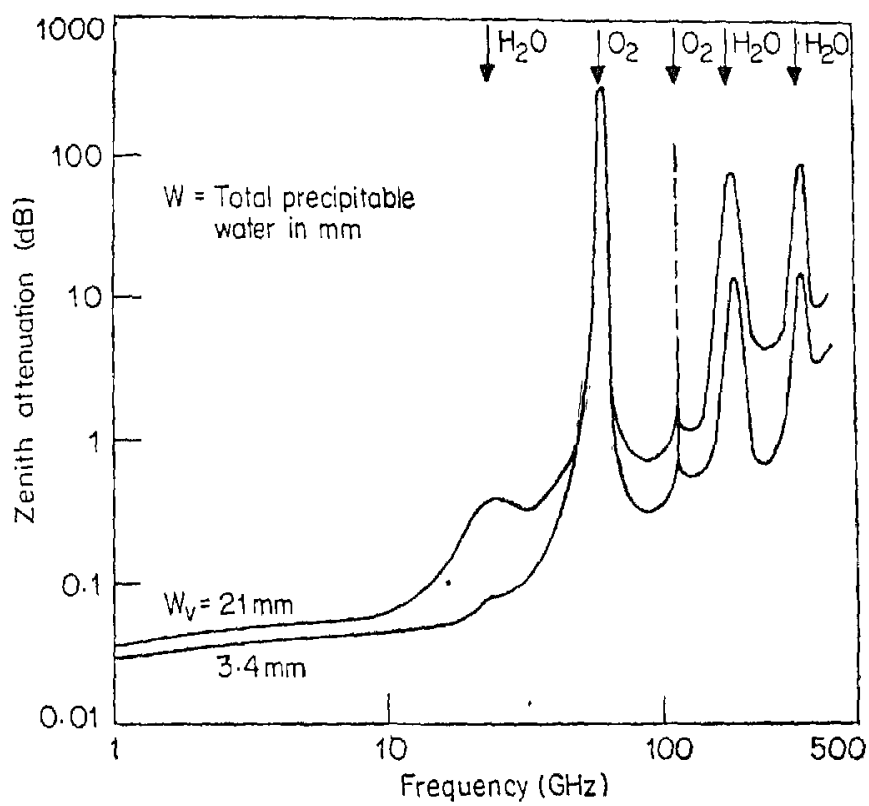

Figure 1. Atmospheric absorption due to water vapour and oxygen [taken from Penzias and Burrus 1973].

latitude $12^{\circ} 58^{\circ}$ ) and Nandi Hills (elevation $1480 \mathrm{~m}$, latitude $13^{\circ} 22^{\prime}$ ) - and to compare them with some of the astronomical sites in Europe and America. These sites were surveyed using a similar type of Infrared Spectral Hygrometer (IRSH) for locating high precision millimeter-wave telescopes that are capable of operating down to very short wavelengths of $1 \mathrm{~mm}$ or less. We discuss here only the results of cloud coverage and water vapour measurements, made at the two sites during the period 1977 to 1979.

\section{Results}

\subsection{Temperature}

During the survey we noted from the recorded meteorological data, the daily maximum and minimum temperatures. The monthly averages of these quantities were compared with similar quantities averaged over the period. 1931 to 1960 (from Climatological Tables of Observatories in India published by India Meteorological Department). The agreement was quite good permitting us to conclude that the period under observation was not exceptional as far as temperature is concerned.

\subsection{Cloud coverage}

The number of clear days and nights during the period $1977-79$ was obtained from the record of hourly cloud data from visual observations. A day was 
considered clear if from $0930 \mathrm{hr}$ to $1500 \mathrm{hr}$ (IST) there was less than 2 octas of cloud, and a night was counted as clear if the same conditions obtained from $2100 \mathrm{hr}$ to $0300 \mathrm{hr}$ (IST). The cloud coverage for the two stations is shown in figures $2 \mathrm{a}$ and $2 \mathrm{~b}$. It may be noted that in the second year of observation there was almost the same number of clear days and nights at Bangalore as at Nandi Hills. During the first year, however, the number of clear nights at Bangalore seems to be greater than at Nandi Hills. The effect of lozal convection around the isolated peak of Nandi Hills is a possible cause. The yearly averages of clear days and nights at both places during the period of observation are shown in table 1 .
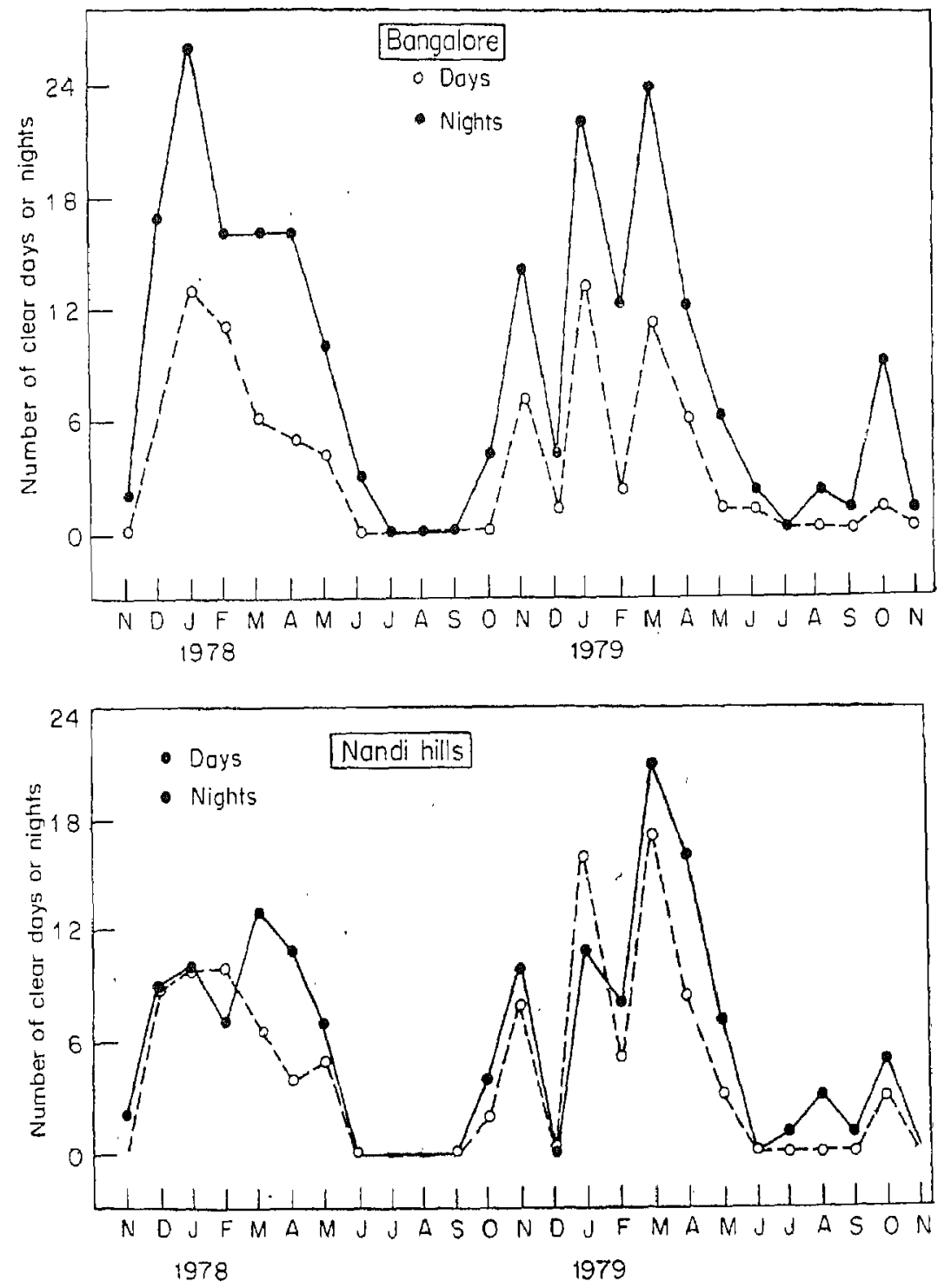

Figure 2. Number of clear days and nights over (a) Bangalore and (b) Nandi Hills during the period of observation. 


\subsection{Precipitable water yapour (PWV)}

The amount of PWV was determined with an infrared spectral hygrometer (IRSH) built at the Mendon Observatory, France, as one of the series used for the SAGMA-IRAM (Scientific Advisory Group for Millimeter Astronomy, now Institut de Radio Astronomie Millimeterique) site survey (1975). The IRSH compares the radiation coming from the Sun in the near infrared at $1.65 \mu$ and 1.85\%. At these two wavelengths the radiation is differentially absorbed. The instrument was calibrated in $\mathrm{mm}$ of $\mathrm{H}_{2} \mathrm{O}$ at sea level by intercomparison with both the master devices of the National Science Foundation (NSF) built by F. Low and that of the National Aeronautics and Space Administration (NASA) built by Westphal (1972) on the one hand, and radiosonde measurements made at Bordeaux (France) on the other.

IRSH measurements were made in alternate periods at Bangalore and Nandi Hills during the winter and premonsoon (October to May) months over two years, 1977-79. On clear days more than 15 mensurements were made from $1000 \mathrm{hr}$ to $1700 \mathrm{hr}$. Radiosonde measurements were also made at the two sites, on 27 days, simultaneously with the IRSH measurements.

Table 1. Comparison of some sites where the IRSHs of the Meudon Observatory were used.

\begin{tabular}{|c|c|c|c|c|c|c|c|}
\hline \multirow{2}{*}{ Site } & \multirow{2}{*}{$\underset{{ }_{N}}{\text { Latitude }}$} & \multirow{2}{*}{$\begin{array}{c}\text { Altitude } \\
(\mathrm{m})\end{array}$} & \multicolumn{2}{|c|}{$\begin{array}{l}\text { PWV (noon) } \\
\text { mun } \mathrm{H}_{2} \mathrm{O}\end{array}$} & \multirow{2}{*}{$\begin{array}{l}\text { Clear } \\
\text { days }\end{array}$} & \multirow{2}{*}{$\begin{array}{r}\text { Clear } \\
\text { nights }\end{array}$} & \multirow{2}{*}{$\begin{array}{c}\text { PWVGG } \\
\text { Non- } \\
\text { Summer } \\
\text { (nmm) }\end{array}$} \\
\hline & & & Summer & $\begin{array}{c}\text { Non- } \\
\text { Summer }\end{array}$ & & & \\
\hline $\begin{array}{l}\text { Bangalore } \\
\text { [India] }\end{array}$ & 13 & 950 & 22 & 20 & 50 & 110 & 26.9 \\
\hline $\begin{array}{l}\text { Nandi Hills } \\
\text { [India] }\end{array}$ & 13.3 & 1480 & 16.5 & 10 & 60 & 75 & 13.8 \\
\hline $\begin{array}{l}\text { Montbel } \\
\text { [France] }\end{array}$ & 44.5 & 1220 & 25 & - & 80 & 100 & - \\
\hline $\begin{array}{l}\text { Bordeaux } \\
\text { [France] }\end{array}$ & 45 & 0 & 27 & 12 & 80 & 100 & 43.5 \\
\hline $\begin{array}{l}\text { Padrille } \\
\text { [France] }\end{array}$ & 42.3 & 2300 & 8 & 5 & 80 & 110 & 15.6 \\
\hline $\begin{array}{l}\text { Bure } \\
\text { [France] }\end{array}$ & 44.5 & 2550 & 4.8 & 1.9 & 100 & 135 & 6.7 \\
\hline $\begin{array}{l}\text { Pico Veleta } \\
\text { [Spain] }\end{array}$ & 37 & 3400 & 3.2 & 1.9 & 100 & 170 & 4.7 \\
\hline $\begin{array}{l}\text { Mauna Kea } \\
\quad \text { [Hawaii] } \\
\text { [Morrison et al }\end{array}$ & $\begin{aligned} & 19.8 \\
1973] & \end{aligned}$ & 4200 & \multicolumn{2}{|c|}{$1.2[\mathrm{AV}]$} & 198 & 204 & 1.8 \\
\hline $\begin{array}{l}\text { White Mountain } \\
\text { [USA] } \\
\text { [Cudaback et al }\end{array}$ & $\begin{array}{r}37.6 \\
1973]\end{array}$ & 4340 & 3.2 & 1.3 & 155 & 190 & 3.3 \\
\hline
\end{tabular}


Radiosondes and the ground equipment were kindly provided by the India Meteorologica1 Department (IMD).

2.3a Accuracy of the measurements: One can obtain an estimate of the error due to the instrument by intercomparing different IRSHs of the same series. Comparing the devices two at a time, it has been found that the relative error of these IRSHs is about 5\% (SAGMA-IRAM 1975).

The primary calibration of the F.Low master was made in a tank whereas the Meudon IRSH was calibrated against radiosonde measurements made at Bordeaux. In the overlapping range from $6 \mathrm{~mm}$ to $20 \mathrm{~mm}$ of PWV, where measurements were made simultaneously, the two curves fit remarkably well. The comparison indicates that at least in the overlapping range, the uncertainty is not much greater than $10 \%$.

Figure 3 compares the data given by the IRSH and the radiosonde working simultaneously at the two sites. The error (standard deviation) in the computed PWV from the radiosonde data is not more than $8 \%$. The agreement is still within $10 \%$. From the above data, we conclude that the amount of precipitable water vapour measured with an IRSH has an accuracy of about 15 to $20 \%$.

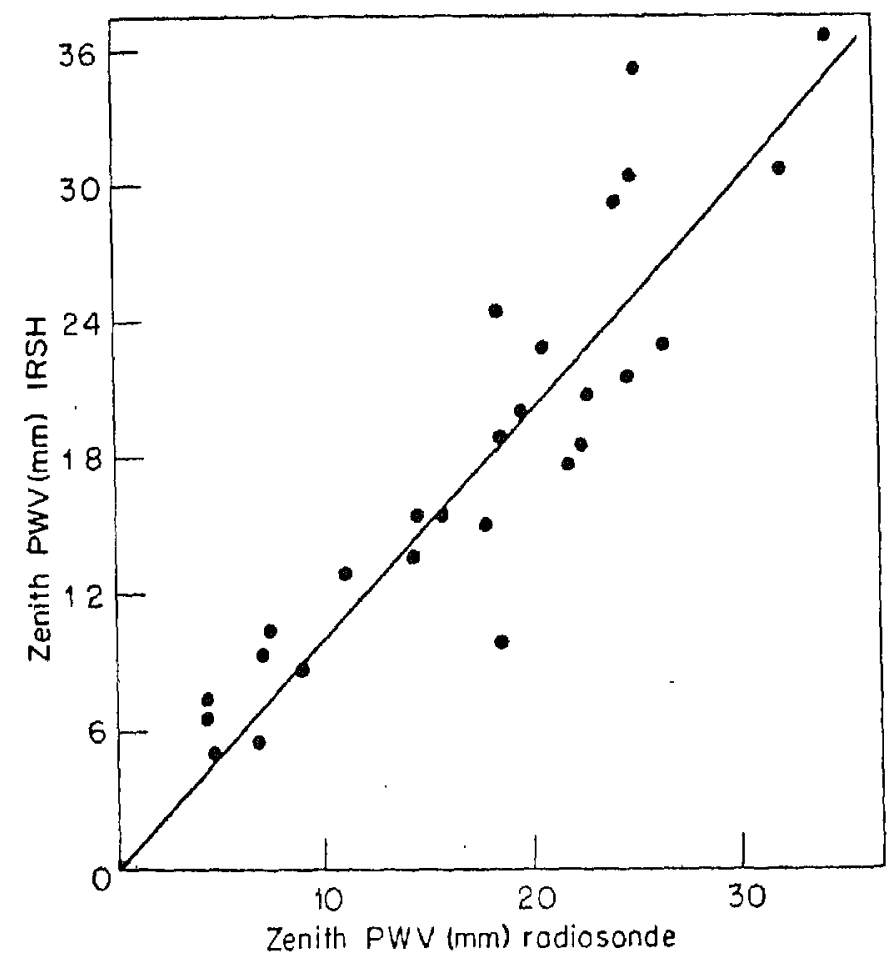

Figure 3. Comparison of PWV given by IRSH and radiosonde working simultaneously. The line drawn is for ideal correspondence between IRSH and radiosonde. 
2.36 Results : Daily mean values of PWV as recorded by the IRSH at Bangalore and Nandi Hills during the two-year period are plotted in figures $4 a$ and $b$ respectively. It can be noted from the figures that at both the sites, the two years a re not identical in respect of PWV, the first year being drier.

The values plotted are the zenith equivalent PWVs; the value given by IRSH is divided by the secant of the zenith angle of the Sun at the time of measurement. To compare these values with those obtained in similar site surveys (Morrison et al 1973; SAGMA-IRAM 1975; Cudaback et al 1973) they must be corrected for pressure broadening effects, i.e. multiplied by $\left(p_{0} / p\right)^{1 / 2}$ where $p_{0}$ is the sea level (calibration level) pressure and $p$ the actual mean pressure of the atmosphere where the measurements are made. This correction becomes important for spectral line measurements; it need not be applied for broadband continuum measurements. An approximate correction factor has been given by Cudaback et al (1973).

As there is a significant annual variation in the zenithal PWV, we separate the summer and non-summer periods (having respectively more and less than the average amount) as has been done in other similar surveys. In addition, we also separate the morning and noon values in order to deteat any possible systematic difference.

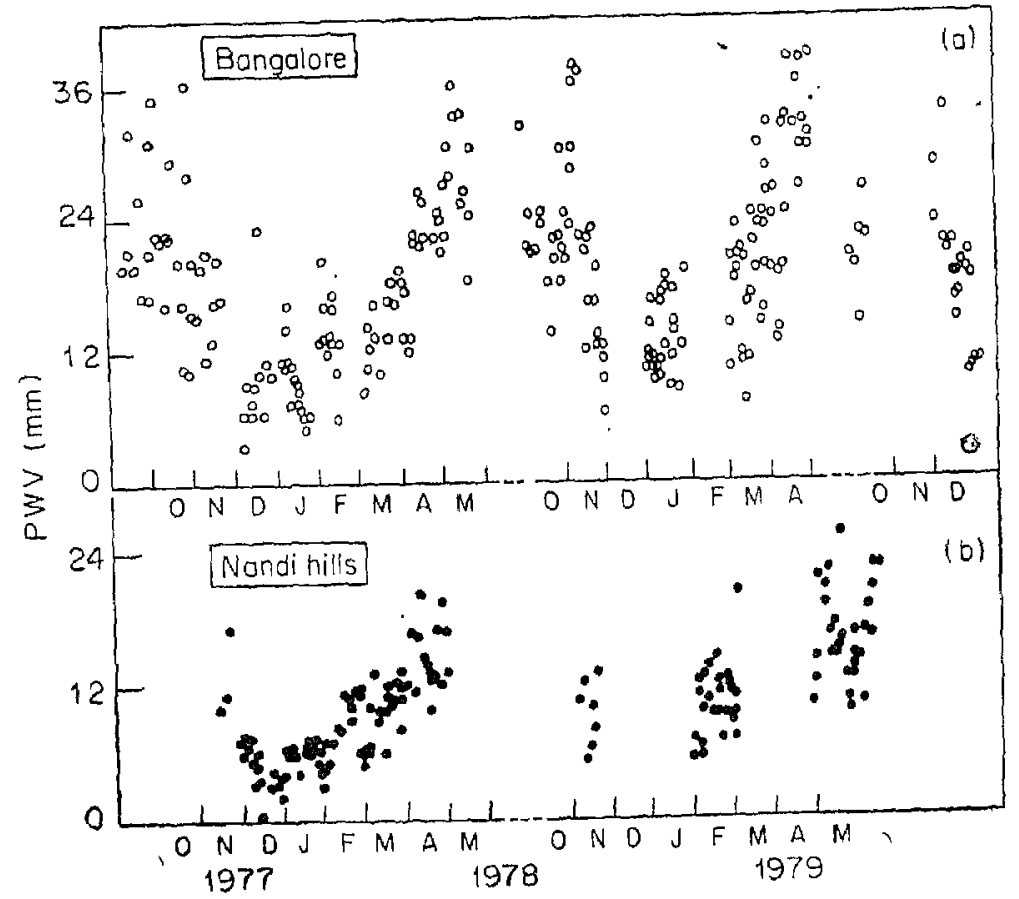

Figure 4. Daily mean values of PWV recorded over the period of two years at (a) Bangalore and (b) Nandi Hills. 
We have plotted the cumulative distribution of zenithal PWV; for $x \mathrm{~mm}$ of PWV the ordinate gives the percentage of time with less than $x \mathrm{~mm}$ of PWV. These cumulative distributions for Bangalore and Nandi Hills are shown in figures $5 \mathrm{a}$ and $\mathrm{b}$. Figures $5 \mathrm{c}$ and $\mathrm{d}$ show similar plots for Bure and La Padrille, France (SAGMA-IRAM 1975). Figures 5e and $f$ show similar distributions for White Mountain, U.S. A. (Cudaback et al 1973) and Bordeaux (Robillot 1980).

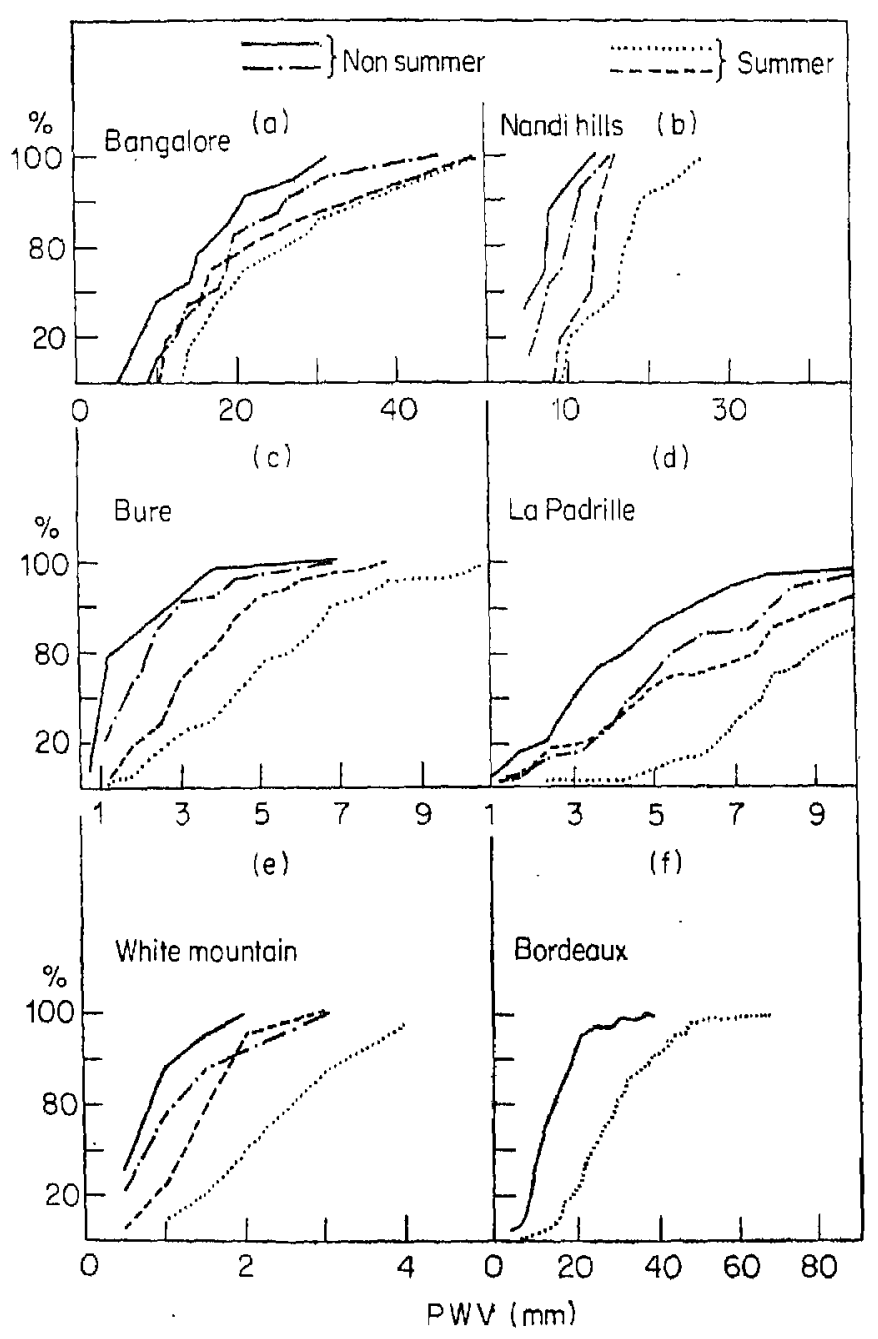

Figure 5. The cumulative distribution of PWV for the stations: (a) Bangalore, (b) Nandi Hills, (c) Bure, (d) La Padrille, (e) White Mountain and (f) Bordealux. (The ordinate indicates the percentage of the time the observed value of PWV is less than the value on the abscissa). 
$2.3 \mathrm{C}$ Deternination of the scale height of $P W V$ : If an exponential distribution of water vapour is assumed, then

$$
(\mathrm{PWV})_{\mathrm{h}}=(\mathrm{PWV})_{0} \exp (-h / H)
$$

where $H$ is the scale height, (PWV $)_{0}$ is the amount of PWV at sea level and $(P W V)_{\mathrm{h}}$ is that at a height $h$. Scale heights deduced from radiosonde data are shown in figure 6 . The scale height is defined as the altitude at which the PWV is reduced to $1 / e$ of the ground level value. From the IRSH measurements at Bangalore and Nandi Hills, we have also derived the scale height of the PWV using the mean values of PWV for the same month at both the places. These scale height values are also plotted in figure 6 . In spite of the fact that the values obtained are averaged over many days, the variability of the scale-height is very large. This can be due to the fact that (1) an exponential distribution is not always applicable, and (2) even when the distribution is more or less exponential, the scale height varies from day to day and more so from winter to summer.

\section{Comparison with a few sites}

Table 1 shows a comparison of some sites where the IRSH's of Meudon Observatory were used. The criterion for a clear day (or night) is not uniform. For Montbel, Bordeaux, Padrille, Bure and Pico Velata the diys (or nights) are considered clear when the sky is covered by clouds less than 2 octas during 6 contiguous hours. For Mauna Kea and White Mountain the figures given in table 1 are from photometric nights and percentage of clear sky over the year (see the references). The criterion adopted for

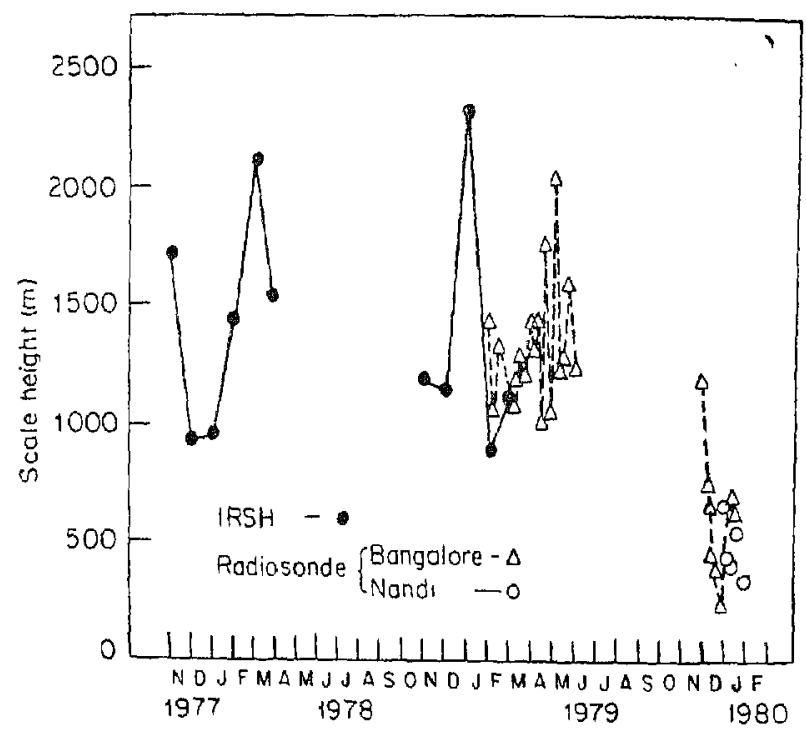

Figure 6. Monthly mean values of scale heights calculated from tadiosonde and IRSH data. 
Bangalore and Nandi Hills leads to a more restrictive amount than for the other sites. The tabulated PWV is the one which corresponds to $50 \%$ of the time in the cumulative distributions for summer and non-summer periods. These PWV values are corrected for the pressure broadening effect.

The last column shows the equivalent PWV in the line of sight to the declination of the galactic center $\left(\mathrm{PWV}_{\mathrm{GC}}\right)$ for non-summer noon.

As all these sites were studied with IRSH instruments of the same series, the comparison is valuable. For the driest sites the absolute accuracy of the PWV is poorer than for others; there are only 30 points of calibration against the F. Low device from $1.2 \mathrm{~mm}$ to $8 \mathrm{~mm}$ of PWV. For these sites the accuracy is about $30 \%$.

\section{Conclusions}

(a) There is a significant variation in the cloud coverage from one year to the next. The number of clear days and clear nights given in table 1 should therefore be taken with caution.

(b) We present measurements made with an IRSH of the PWV above two Indian sites at low latitude $\left(13^{\circ} \mathrm{N}\right)$. The period of the survey (more than 2 years) and the number of observing days recorded (262 for Bangalore, 155 for Nandi Hills) make the survey statistically significant.

(c) The measurements show:

(i) a substantial variability in the PWV

(ii) a diurnal variation of about $50 \%$ (from early morning to late evening) which indicates that the night time is drier than the day time

(iii) a day-to-day variation

(iv) a yearly variation of about $300 \%$. It should be noted that there is a variation of the annual cycle with latitude (there is more than 5 months of the summer period at $13^{\circ} \mathrm{N}$ against 3 to 4 at $45^{\circ} \mathrm{N}$ )

(d) It appears that on isolated peaks there is a depletion of PWV compared to the surrounding area. This is true at Hawaii, Bure and Nandi.Hills. A convective effect is presumably responsible for this depletion.

From (c) and (d) mentioned above it follows that it is not clear how to define a scale height for the PWV, and particularly so in mountain areas. This might well account for the poor correlation (from 0.39 to 0.89 ; Roosen and Angione 1977) between the values of PWV evaluated by IRSH or balloons with those determined from surface humidity measurements.

\section{Acknowledgements}

The authors are grateful to the meteorological team of the Raman Research Institute who made the surface meteorological measurements, organised the 
radiosonde flights, and helped in the collection of the IRSH data. They thank Mr N V G Sarma for many helpful discussions during the preparation of the paper. Thanks are also due to the Indian Meteorological Department for providing the ground equipment on loan and supplying the radiosondes on payment. The authors are indebted to Mrs Gadea of Meudon Observatory who drew the graphs.

\section{References}

Cudaback D et al 1973 NASA Report "An Infrared Observatory for White Mountain" Gibbins C J, Gordon-Smith A C and Croom D I 1975 Planet Space Sci. 2361

Greve A 1978 Infrared Phys. 18127

Morrison D et al 1973 Pub. Astron. Soc. Pacific 85255

Penzias A A and Burrus C A 1973 Ann. Rev. Astron. Astrophys. 1151

Robillot J M 1980 Private Communication

Roosen R G and A.ngione R J 1977 Pub. Astron. Soc. Pacific 89814

SAGMA-IRAM 1975 Final Report on the SAGMA (IRAM) Site Survey Paris-Bonn

Webster W J 1975 Goddard Space Flight Centre Publ. 10-922-75-107 Greenbelt, Maryland

Westphal J A 1972 NASA Report "Preliminary Report of the ten micron infrared sky survey" 